\title{
Architectural Features of Stilted Buildings of the Tujia People: A Case Study of Ancient Buildings in the Peng Family Village in Western Hubei Province, China
}

\author{
Kui Zhao ${ }^{*}$, William L. Tilson ${ }^{2}$, Dan Zhu ${ }^{3}$ \\ ${ }^{1}$ School of Architecture \& Urban Planning, Huazhong University of Science and Technology, Wuhan, China; ${ }^{2}$ School of Architecture, \\ University of Florida, Gainesville, USA; ${ }^{3}$ Urban and Regional Planning, University of Florida, Gainesville, USA. \\ *Corresponding author: yuyu5199@126.com
}

Received October $7^{\text {th }}, 2013$; revised November $28^{\text {th }}, 2013$; accepted December $8^{\text {th }}, 2013$

Copyright (c) 2013 Kui Zhao et al. This is an open access article distributed under the Creative Commons Attribution License, which permits unrestricted use, distribution, and reproduction in any medium, provided the original work is properly cited. In accordance of the Creative Commons Attribution License all Copyrights (C) 2013 are reserved for SCIRP and the owner of the intellectual property Kui Zhao et al. All Copyright (C) 2013 are guarded by law and by SCIRP as a guardian.

\begin{abstract}
This paper describes and analyzes the stilted buildings of the Tujia people (an ethnic group living in mainland China), a distinctive building style unique to them, from the perspectives of site selection, spatial layout, construction techniques, and cultural inheritance. The cluster of stilted buildings (Diaojiao Lou in Mandarin Pinyin) in the Pengjia Village (meaning most of the villagers share the surname of Peng) is presented as a case study in this paper. The paper makes a case for their preservation as authentic carriers of the Tujia people's cultural history, which is quickly disappearing due to development pressures. Three preservation strategies are discussed to meet this preservation goal. The first is to provide a detail analysis of the construction language to guarantee authenticity in the documentation, preservation and restoration processes of the stilted buildings. The second is to keep alive the expert knowledge and skill of traditional artisans by involving them in the construction of new structures using diaojiaolou techniques. The third strategy is to encourage local people to "dress-up" discordant buildings constructed mid to late 20th century with well-mannered facades using traditional details such as suspension columns, shuaqi, and six-panel and bang doors. Taking as a whole, these strategies are presented to help local residents, preservation experts, developers and policy makers sustain the irreplaceable cultural heritage and economic independence of the Tujia people.
\end{abstract}

Keywords: Tujia People; Stilted Buildings; Ancient Architecture Surveying; Traditional Structural Features; Traditional Spatial Features

\section{Introduction}

Stilted buildings are unique to the Tujia people living in the mountainous region of western China, including Hubei Province, Chongqing municipality, Hunan Province, and Guizhou Province. They are typical architectural structures carefully adapted to the local ecology, environment, and geography, characterized by steep mountains and wood-covered topography, a moist and rainy climate, extremely hot summers, and severe winters $[1,2]$. The stilted buildings clearly represent the folk customs, and the artistic, cultural, and aesthetic preferences of the Tujia.

The stilted buildings in the Peng Family Village (Pengjia Village) in the mountains in Xuan'en County in the west of Hubei Province are the most typical representatives of such buildings [3]. The village is not easy to reach, and they are preserved in perfect condition due to their remote location. During the summer holiday of 2012, a team from Huazhong University of Science and Technology (HUST) surveyed the cluster of ancient stilted buildings hidden in the remote mountains in order to reveal the mystery of the Tujia Village.

\section{Site Selection}

The site selection of Pengjia Village represents the most intact cultural and building practices of all Tujia villages. There are more than 200 villagers in the 45 households in Pengjia Village [4]. Most of the villagers emigrated from 
Hunan to Hubei Province by following the Youshui River, the most important river west of Hunan and Hubei Province. Most of the Tujia people live along the Youshui River, which they refer to as their "mother river" [5] At the end of the Qing Dynasty and during the 18th to the 20th centuries, the river was employed as the most important channel to transport salt from Sichuan Province to Hubei and Hunan Province [1]. Today, many elderly people still remember their experience of shipping salt to Pengjia Village. In the 200-year period when transporting salt was a major enterprise, there have been a few waves of immigration, which resulted from the growing population in the region. The immigrants maintained a primitive and self-sufficient way of life through farming and weaving; they lived in a closed region with little exchange and communication with the outside world aside from salt transport.

Along the banks of the Youshui River are more than a dozen Tujia villages such as the Wang Family Village, Zeng Family Village, Luo Family Village, Wu Family Village, and Baiguoba Village. The salt shipping and production are not only the pillar industry of the Tujia people, but also result in the popularity of the stilted buildings in this region.

Most importantly, the Peng Family Village has fostered the most beautiful and well preserved stilted buildings of the Tujia. The village lies on the south of the so-called Lotus Seat of the Goddess of Mercy (KwanYin) at the foot of Kwan Yin Mountain. On the west of the village is a deep and long stream, over which there is a century-old wind-rain bridge (a local style of bridge that has a small structure built on the bridge to avoid wind and rain). The clean and transparent Longtan River (one of the tributaries of the Youshui River) flows through the village in its front section. On the Longtan River is a 40-meter-long and 0.8-meter-wide woodboard-paved cable bridge connecting the village to the outside world. Behind the village are steep hills and mountains covered by dense bamboo forests. Walking downstream along the Longtan River, you will witness the Lion Rock, Shuihong Temple and another village called Wangjia Village. The Pengjia Village and Wangjia Village both emigrated from Hunan province (Figures 13).

Viewed from afar, one is easily overwhelmed by the artistic glamour of the exquisite cluster of stilted buildings of the Peng Family village. Over nine buildings on piles stand on the front and rear sections of the village, which feature cornices, rake angles and traditional Chinese exterior decorations. There are also another dozen pillar-supported dwellings at the end of the stilted buildings closest to the mountain. The space in the pillars is

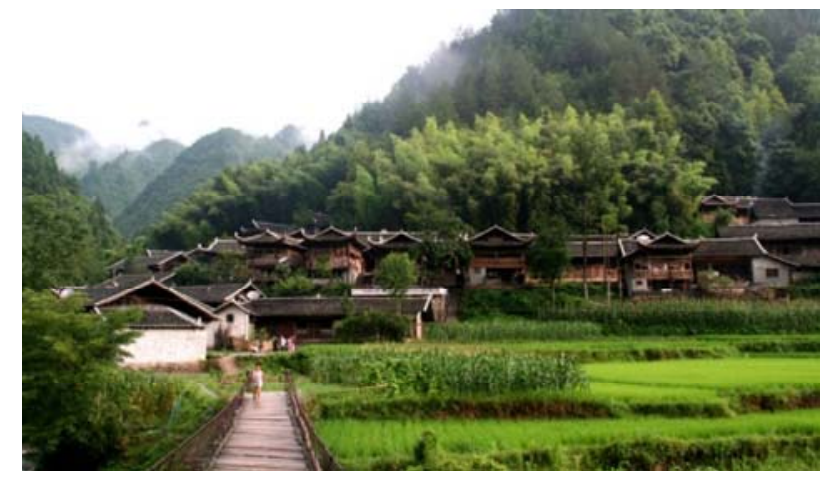

Figure 1. Distant view of the cluster of stilted buildings picture by Kui Zhao, 2013.

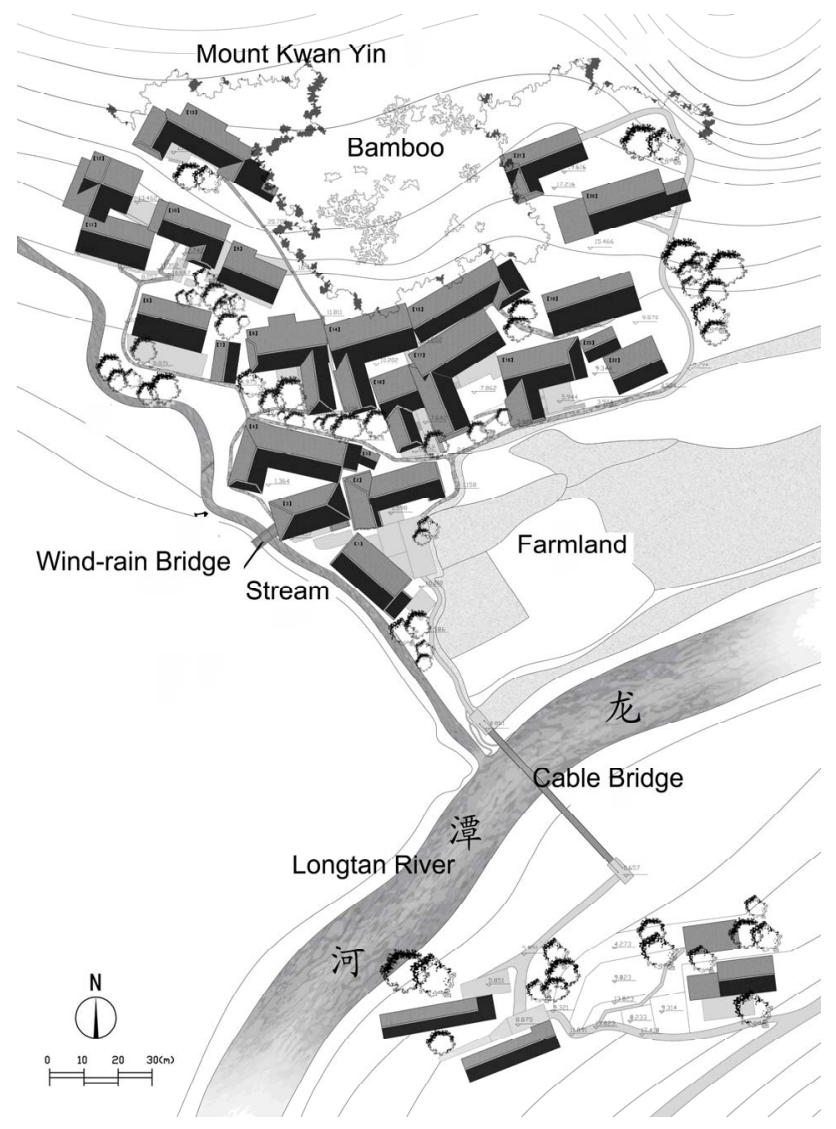

Figure 2. Site plan of Peng Family Village picture by Kui Zhao, 2012.

used as a passageway, warehouse, or stables and pens for cows and pigs. Most of the stairways and courtyards in the village are paved with precisely cut and well-maintained local slate. The stilted buildings and space in the courtyards are quite well-ventilated without the odors of the adjacent stables [6,7]. Even in summer, they provide a cool and dry environment, which is perfect for the moist and hot summer climate in western Hubei Province. 


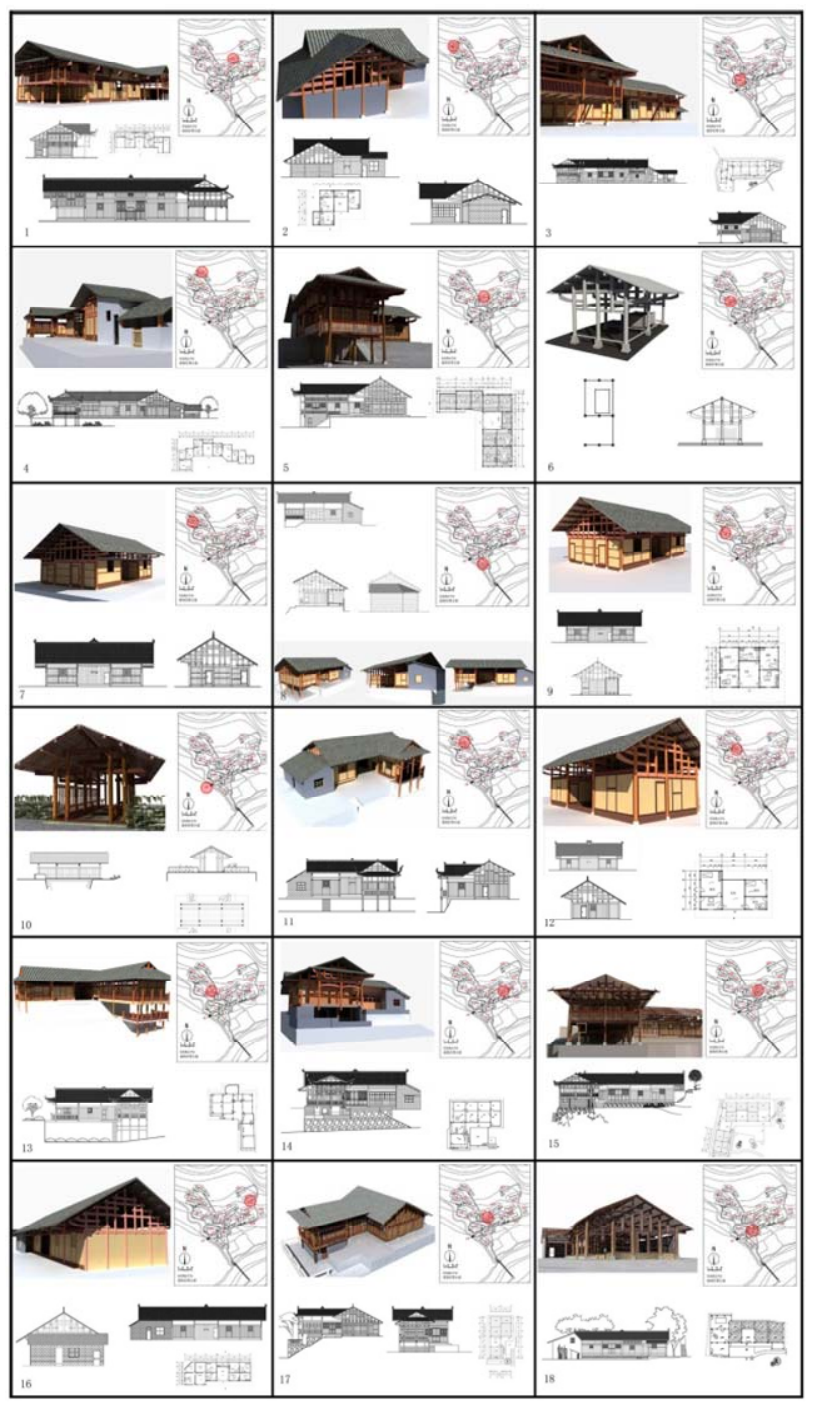

Figure 3. Stilted buildings of Peng Family Village drawing by Kui Zhao, 2012.

The Peng Family Village was built in front of the mountain, close to the water. The streams flowing on its sides form the borders of village. With the square shape, the village is the typical site selection of the Tujia people settlements.

\section{Structural Features of Stilted Buildings}

The stilted building is a kind of structure of through type timber frame that adapts to the topography in the mountain areas. Since there is an empty space in the lower level or slope of the hillside, the space is supported by many wooden columns that form the corridors under the huge roof and overhang balcony. The outmost columns are slender woods that are suspended from the roof and do not reach the ground. It seems that all the buildings are suspended by slender wood, which is the reason why they are called stilted buildings. Though different from the ordinary pillar-supported buildings, the stilted buildings can still be labeled as special pillar-supported ones. We will explain the structural differences by taking as an example, the 3-dimensional anatomy model of a stilted building with the quasi-pavilion (Figure 4).

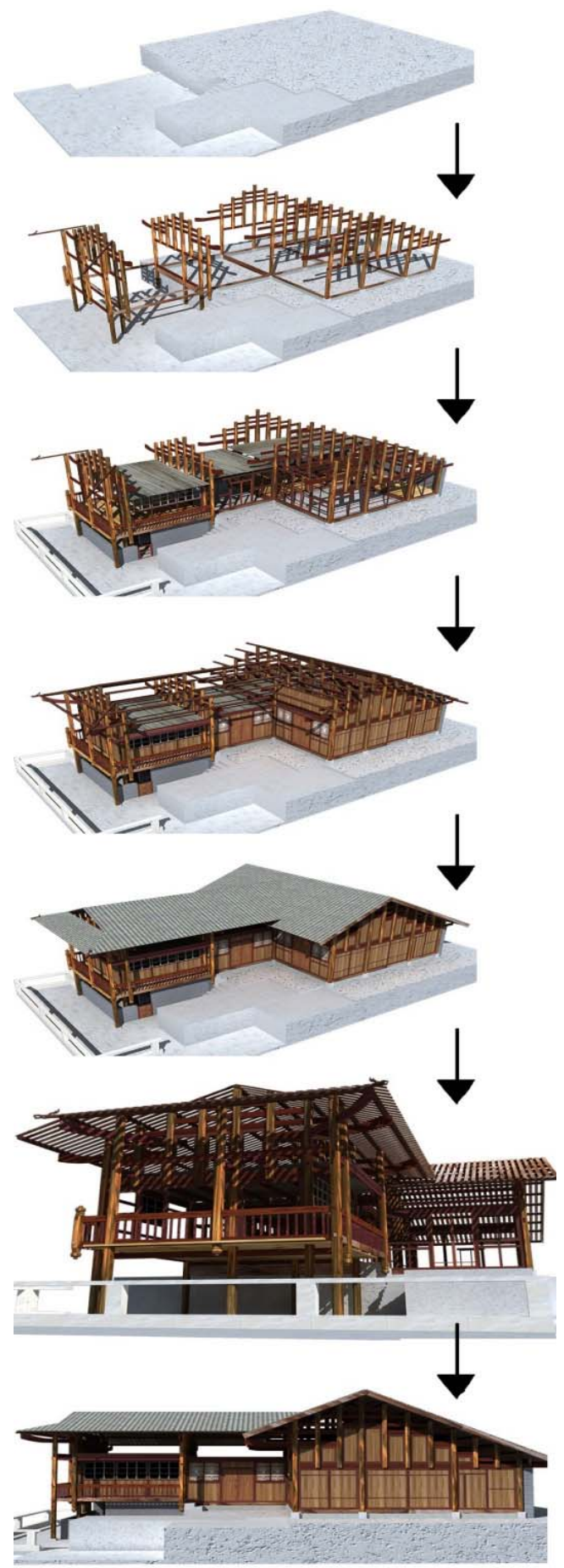

Figure 4. Construction process analysis computer modeling by Kui Zhao, 2007. 
This stilted building is shaped like the letter L. It has the typical typology composed of one principal house and one wing. The foundation of the wing is lower than that of the principal house, and the lower level of the wing is suspended to form the quasi-pavilion. Some peripheral columns supporting the quasi-pavilion are not rooted on the ground. These columns are called stepsupporting columns or suspension columns, whose weight is supported by the beams among the peripheral columns sitting on the floor or by the extrusions among the side columns [6,7]. The beams in the periphery of the quasi-pavilion are paved with wood boards to form the suspended corridor, at the end of which are the suspended short columns as the support of the corridor railing. These supports are called "Shuaqi". "Shuaqi" not only act as a support function, but also play an important role in decoration. The "Shuaqi" and the head of the suspension peripheral columns are shaped like balls or pumpkins, known as "head of Shuaqi" or "golden melon" by the local people. Because of their adjacency proximity to persons' viewport, the "golden melon" is one of the most important structural components of the decorations of Tujia buildings. The exterior sections of the square beam beyond the peripheral columns are called the "overhanging beams", which support the cornices. Because the cornice in the stilted buildings is often quite large, the supporting beams usually have two layers, forming the double-beams structure. The upper beam of smaller size is called the secondary beam, with the lower beam supporting the majority of the weight; thus it is called the primary overhanging beam. The primary beam often uses the naturally-bending trunk of large trees for the sake of weight holding. Sometimes the primary beam is shaped like a broadsword or a horse head. Thus, it is often called the "broadsword beam" or "horse head beam" [8]. The size and bending of the primary and secondary beams are significant for the gradient of the roof and design of the cornice (Figure 5).

Some Tujia buildings have transformed the double-beam structure into the "short-pillar structure" by adding a "short-pillar" on the overhanging beam, which the local people call a "stool pillar" [10]. On the ends of stool pillars are purlins that support the weight of the cornices. The primary overhanging beams go through the short-pillar and transmit part of the weight to the secondary small beams. Thus, the double beams and the short pillars collaborate to form a "stool pillar" to take more weight than the double beams do, making the force more rationally arranged. There are many other kinds of tectonic evolutions based on "double beams" and "stool pillar", such as "oblique beam" and "double pillar" [9, 10]. These designs have made the structure complex. Just like the "heads of Shuaqi", the ends of the "stool pillars"
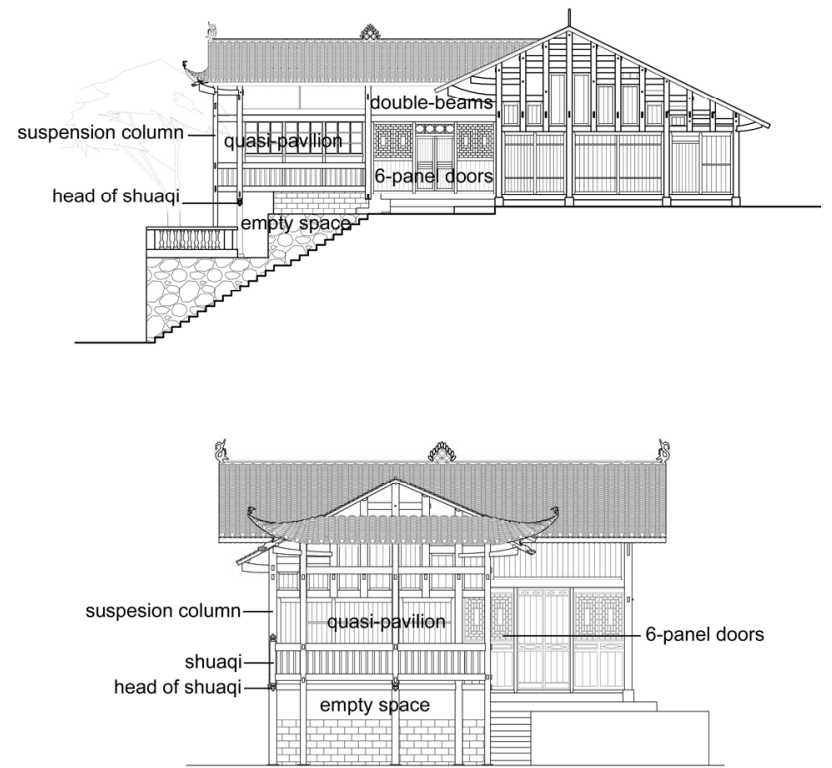

Figure 5. Façade map of the stilted building drawing by Kui Zhao, 2013.

are shaped in different designs and become the important decorations in Tujia buildings (Figures 6 and 7).

The quasi-pavilion, suspension peripheral columns, double-beams, stool-pillars, Shuaqi, handing columns, heads of Shuaqi and ends of hanging columns have become the most evident symbols of stilted buildings of the Tujia. The most distinctive scene of the stilted buildings in Pengjia Village is the row of quasi-pavilions along the foot of the mountain, presenting the most attractive and unique features of these buildings. Additionally, the cornice on the roof of the quasi-pavilions, catering to the elevation and light quality of the buildings, extrudes upward on the four corners and seems to be flying. These designs have made the façade highly animated and are typical of the Tujia buildings.

\section{Details in the Buildings}

\subsection{Windows and Doors}

The windows and doors in the stilted buildings in Pengjia Village are one of their most attractive features as serve as a tangible symbol of the Tujia people's wisdom and diligence in craft [10]. Though they are not as sophisticated and dignified as the windows and doors of the houses in Anhui Province, they are still known for their ancient, profound and diversified style, presenting the most delicate example of Tujia craftsmanship (Figure 8).

Most of the Tujia doors to the principal sitting room have six door panels that are 2.8 meters high and 5 meters wide. These six door panels, installed via the door spindles, form three doors to the room. The ends of each panel have the penetrating or relief flower-shaped 


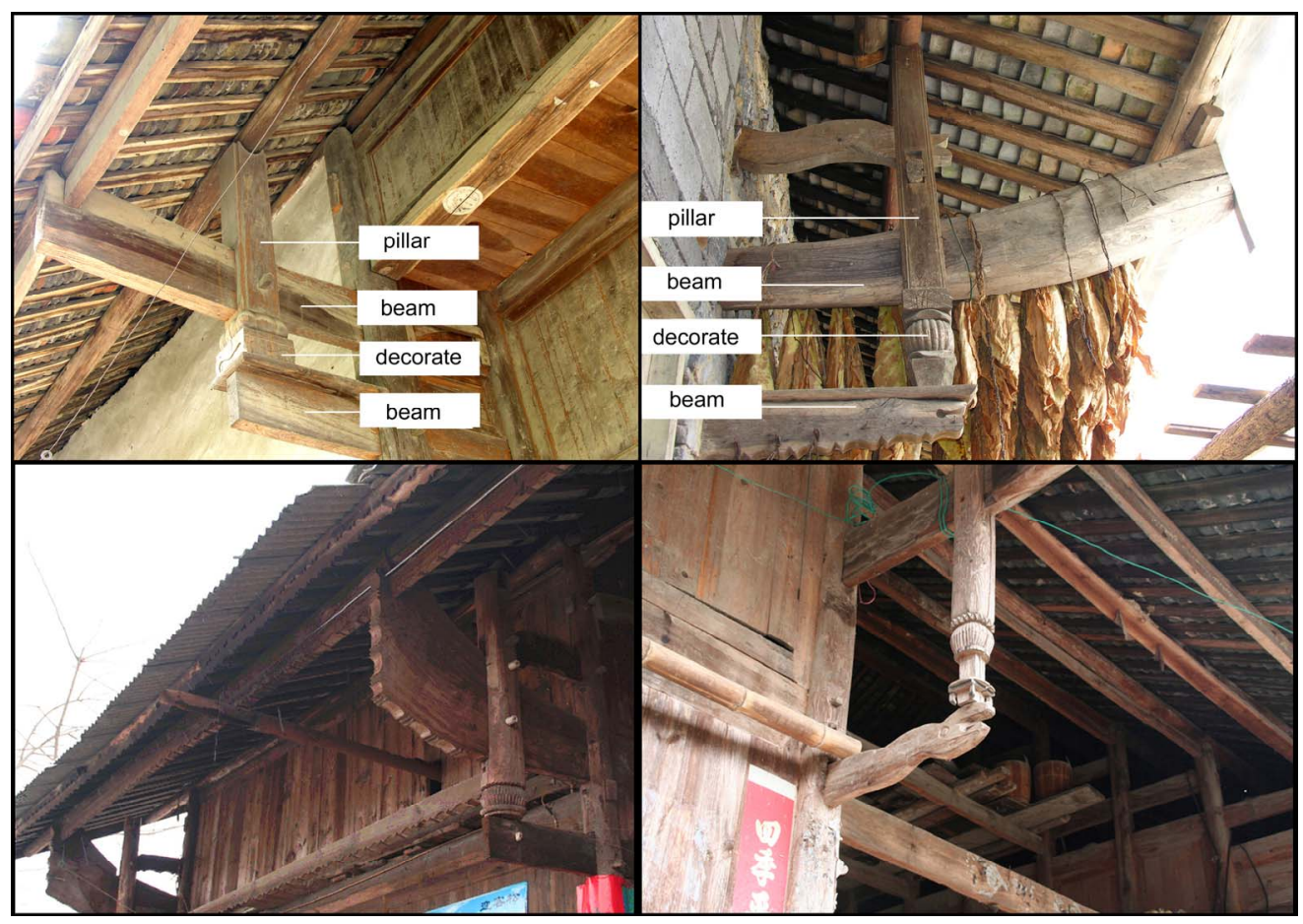

Figure 6. The decorations of stool pillars picture by Kui Zhao, 2011.

sculptures. In the middle section of the panel are the door windows of various designs. The 6-panel doors are sometimes fake. The genuine 6-panel doors can be opened forming three passages for people of different age and status in the family. During the Spring Festival when the villagers play the "lion lantern" $[9,10]$, if the team fails to enter the doors following the proper etiquette, they will find it difficult to leave the room. The fake 6-panel doors, though they also have the same structure, have the panels on the sides simply fixed and not operable, leaving only two doors in the middle that can be opened. Some villagers would install two smaller door panels beside the 6-panel doors for the passage of chickens and dogs. The smaller door is 1.1 meter high and 1.7 meter wide. It is made of the timber of the Cedrela chinensis or "nut tree" $[11,12]$. Owing to the safe environment in the village, some houses are not equipped with the 6-panel doors and only have the smaller doors.

The secondary room is often equipped with only one wooden door with two panels. The other rooms use the single-panel door. There are two types of single-panel doors. One is the "embedded door" $[9,10]$. When closed, the door panel is perfectly imbedded into the door frame. The other is the "bang door" $[9,10]$, because the door panel is larger than the door frame, and it will produce a "bang" noise when closing the door, which often results in the clash between the door panel and frame.

The windows are obviously used for lighting and ventilating; however, the windows in Pengjia Village have been given cultural content by the Tujia carpenters. These windows are shaped like Chinese characters. The door windows are shaped in a rectangle while the wall windows are square. The window designs are often symmetrical horizontally or vertically. The carpenters often make drawings first, then construct 3-cm patterns in a tenon-and-mortise design and connect the patterns to form the windows.

The window design reflects the craftsmanship and individuality of the Tujia carpenters and represents the pursuit of the Tujia people for a happy life. Every window design made of the patterns has its own meaning. Some carpenters even shape the patterns into sophisticated designs or animals. These designs are vivid and captivating even to those who do not understand their precise cultural meanings.

Unfortunately, there are only a few carpenters left in Pengjia Village who are trained in these traditional techniques. The owner of the house where our team lived was just such a carpenter. He lamented the loss of window carving techniques, saying most of the carpenters today have failed to inherit the traditional techniques and skill. Old carpenters make the windows with their own hands, but this distant village in the depth of mountains has been greatly influenced by the modern technologies. The young carpenters today mainly use machines to cut the battens, which are uniform in size and shape. However, when we measured the structural components of the ancient buildings, we found some components had different 


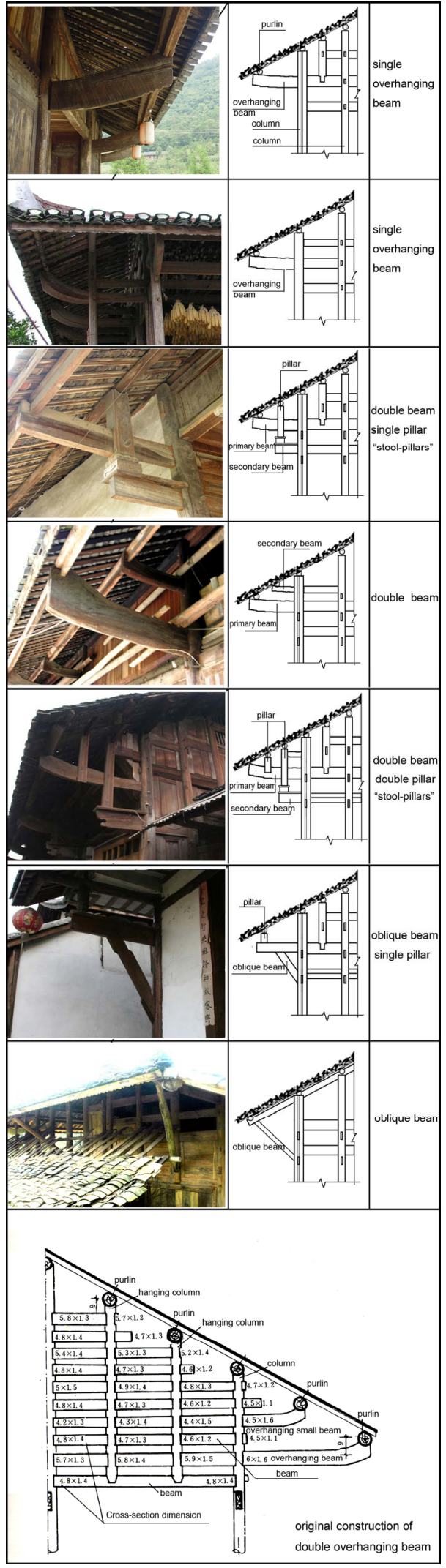

Figure 7. Tectonic evolution of double-beam structure; photo \& drawing by Kui Zhao, 2008.

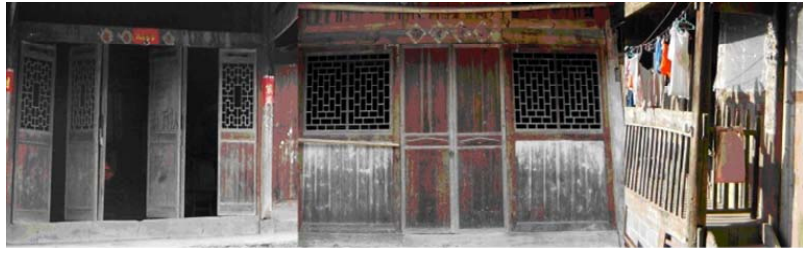

Figure 8. The real 6-panel door, the fake 6-panel door and the single-panel doors picture by Kui Zhao, 2007.

sizes. Probably the aesthetic attractiveness of the artisanship cannot be realized by the components made by the machines.

\subsection{Roof}

The building roofs in the Tujia villages produce an exquisite flowing visual effect. Seen from the vertical exterior layout, the buildings form the anatomy featured by touching the sky but staying away from the floor and the even top level but uneven floor level [11,12]. Such section planes are formed by adopting the techniques of suspended roof, omitted levels, and overlapping levels. As a result, viewers will sense the lively and vivid feeling without dullness or rigidity. The roof of the single stilted building is not complex in itself. It is often shaped like "_" or "L". Sometimes, the huge dark grey roof, the significant cantilever of the cornice, and the suspension space in the lower level will form the unstable composition of "heavy head and unstable feet". When the numerous facades are viewed in a cluster, however, the buildings become balanced, solemn, elastic, and rhythmic, producing a generous and profound aesthetic sense. If we see the overall layout of the Tujia stilted buildings, we will find them in an irregular and elastic cluster. Some houses are built catering to the topography of the mountain. Some produce overlapping layers of structure. Others are built on the edge of valleys. Many are lively and vivid, and a select number are sublime because of their positions on the hilltop.

Most of the stilted buildings in Pengjia Village are built at the foot of the mountain or hill. The narrow space under the cornices and the stairways following the ups and downs of the topography often produce the atmosphere of suddenly a village emerges in the eyes when people are wondering whether they have lost the directions $[13,14]$. Because of the large height difference in the site area, the large roof of the front building often surrounds the outdoor terrace of the rear building. Looking down from the suspended balcony of the higher building, you can see the overlapping and continuous roofs, looking like a rolling hill. These roofs seem to be surrounded by a crystal stream, a suspension bridge, yellow farm fields, and a huge, green mountain, which form fantastic rural scenery (Figure 9). 


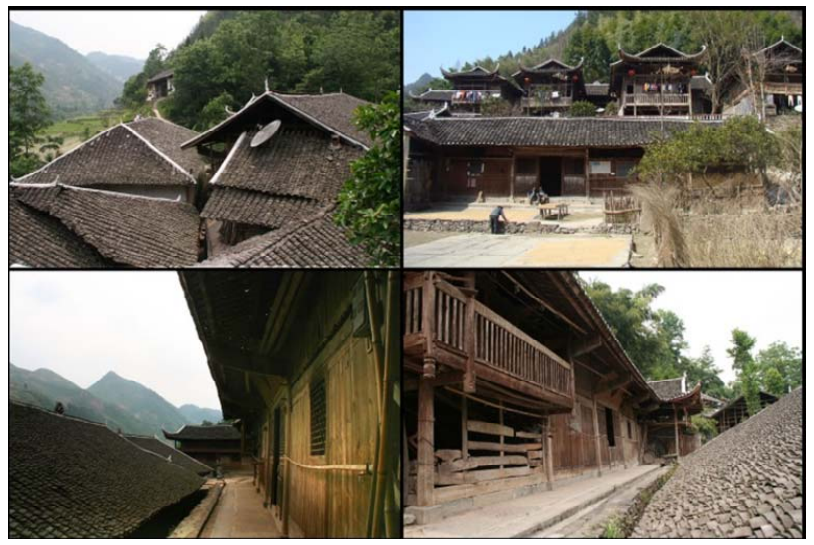

Figure 9. Roofs view of the cluster of stilted buildings picture by Kui Zhao, 2013.

\subsection{Shrines}

The Tujia buildings are cohabited by human beings and immortal beings [16,17]. The Tujia people must locate space in their homes to worship the immortal beings and their ancestors. These spaces are often set in the shrines or places equivalent to shrines, in the principal sitting rooms. Often sacred spaces are placed in the kitchen. People also believe that the immortal beings live in the stables, mills, workshops, or corners in the house $[16,17]$. In addition, different ethnic groups allocate different spaces in the house as shrines and adopt different functions and shapes for the shrines, which become an important symbol identifying the ethnic group (Figure 10).

The shrines in the Peng Family Village are often placed on the rear wall in the principal sitting room, in the middle of which is installed a wood board called a "shrine platform" to worship Grandfather Nuotuo and Grandmother Nuotuo believed to be the ancestors of Tujia people [15]. On the platform are placed the incense burner, candles, and straw paper. On the top of the shrine is another piece of wood board called a flame board, used to prevent against fire. Apart from the above-mentioned hardware in the shrine of the Tujia buildings, there is also the ancestral list describing the hometown and name of the ancestors pasted on the middle of the platform and the flame board. After everything is set, the priest of the Tujia people will be invited to hold ceremonies to usher in the immortals beings or ancestors into the shrine. After this ritual is completed, the space becomes a genuine shrine.

\section{Spatial Features of the Buildings}

The Tujia villages have the distinctive spatial forms composed of the narrow lane space in the village, the space under the cornices and the courtyard space surrounded by the roof, and the building and the environmental space beyond the village.

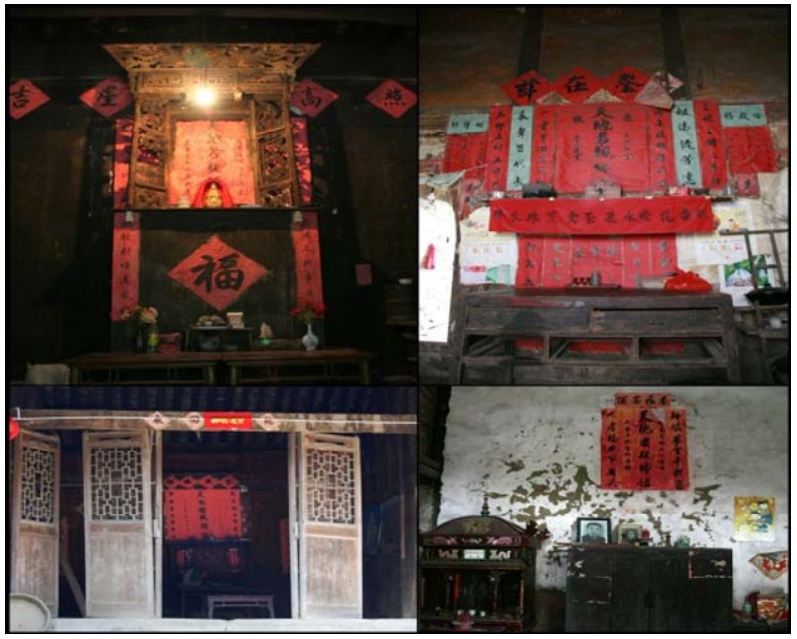

Figure 10. Shrine picture by Kui Zhao, 2007.

The villages of the Tujia people are often built on the river with a certain distance from the river; this distance can provide the buffer area when the flood comes. In addition, the farmland in the buffer area is fertile and becomes an excellent growing place for crops. The entrance roads to the villages are also built on the south bank of the river, making the river the natural protection for the villages. The sequence of the village layout is composed of the hill roads, river, suspension bridge, farmland, village, bamboo forests, and mountain in the background. Such a spatial layout has formed the diversified and complex exterior space of the village.

Walking into the village, crossing the winding lanes and stepping onto the stairways, you will enter the compact and diversified space in the single stilted buildings.

The stilted buildings have many forms; "-_" shape, "L", and "U" shape are very popular. The Tujia people choose different styled dwellings according to the complex changes of the topographic landforms. They usually build dwellings parallel to the contour line of the mountain or hill, but still, many stilted buildings are built vertical to the contour line because of the limited site area in mountain rural area. The typical stilted building can be divided into two parts: one is set on a higher level, another on a lower area. The residential area in higher level has the sitting room and bedroom, and vertical to it is the suspended building. The suspension space in the lower level has the toilet, bathroom, and pigpen. The second floor, which connects to higher areas, has the dining room, kitchen room and another bedroom. By taking some typical stilted buildings in Pengjia Village as an example, we summarize their spatial features as follows (Figures 11 and 12).

Every building has many rooms, and every room is linked to each other. The sitting room is the most important space, which has many doors on the walls in each 


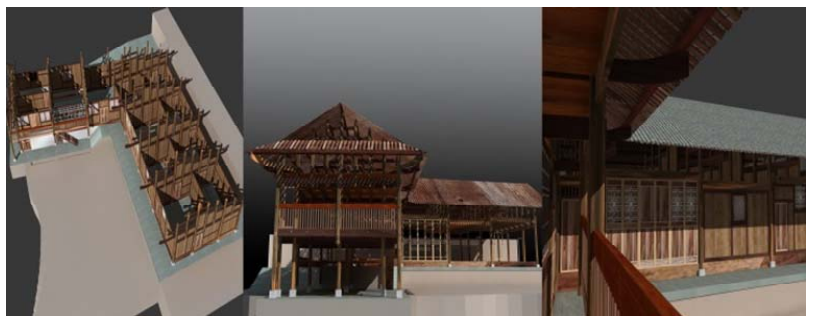

Figure 11. Analytical model of the single stilted building Modeling picture by Kui Zhao, 2010.

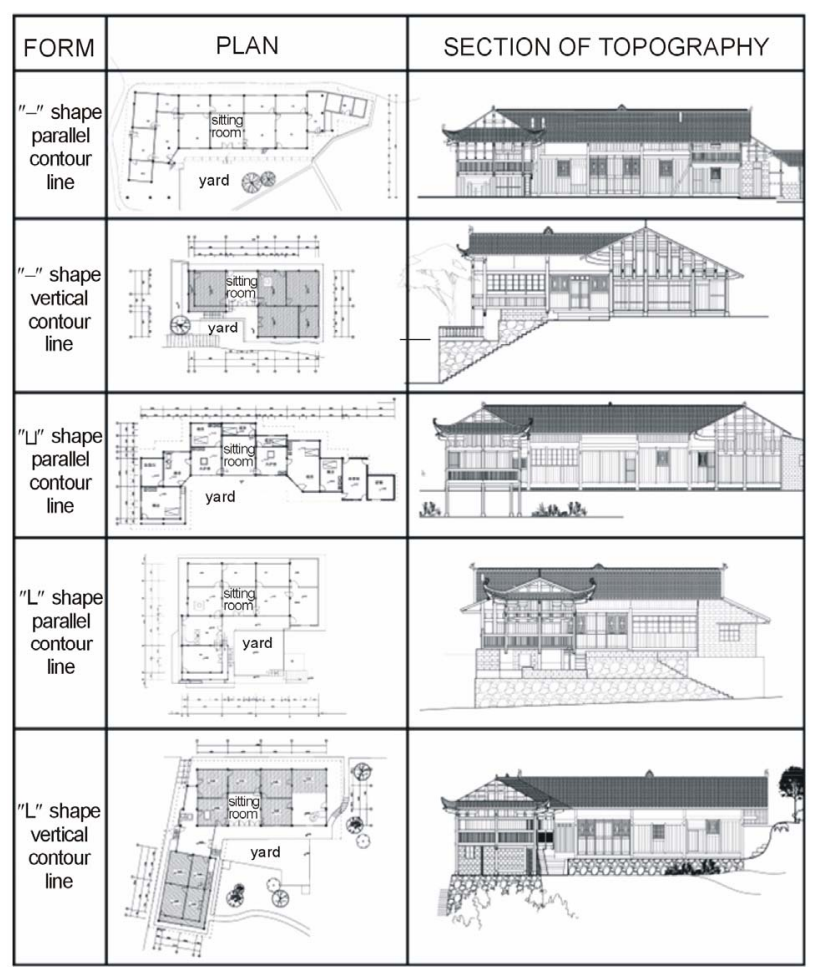

Figure 12. Analysis of plane and section of stilted building drawing by Kui Zhao, 2010.

direction. The other private rooms, such as the bedroom, often have two doors that provide access to it. It represents that the family is cohesive but does create an ambiguous awareness of privacy.

In winter, people flock together around a brazier (which is a large braze container in which charcoal is burned) in the center of the sitting room. Under the sitting room floor is empty, so the warm air flows into the empty space keeping the inside room warm. It is a simple but efficient folk technology (Figure 13).

Sewage is strictly separated from the hygienic areas. To make better use of the space in lower level, the stable and toilet that produce odor and sewage are often placed in this level. Thus, the wood structure of the higher level can remain dry and hygienic for the whole year. The stilted buildings also separate the inhabitants from the many insects and poisonous snakes living on the hill

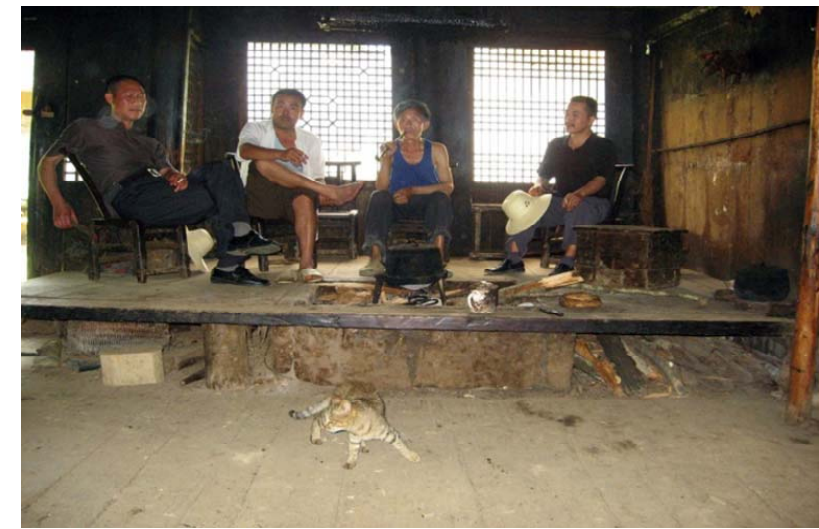

Figure 13. warm floor in sitting room picture by Kui Zhao, 2013.

slopes. The courtyard serves as the transit space for transport of goods. The rooms are arranged on the hill slope, and consequently, they may not be reached by directly by walking. The courtyard is often used as a temporary storage space. The 2 meters wide stone paving is beyond the extended cornice, and the cornices are used as the shelter against rain and strong sunlight when people walk on them.

\section{Conclusions}

The Tujia people's stilted buildings have their own ethnic distinctiveness in construction, such as the quasipavilion, suspension peripheral columns, double-beams, stool-pillars, and huge roof, balcony and cornices. The most distinctive feature is that many wooden pillars, which help the inhabitants adapt to living in mountain environment, support the buildings. High above the ground, stilted buildings have the following advantages:

First, it can keep people away from deadly dangers, such as miasma, poisonous vegetation, venomous snakes, and huge wild animals.

Second, people can stay away from the humidity close to the ground and prevent humidity related diseases.

Finally, there is better lighting upstairs, so people can work on delicate handcrafts or simply enjoy the light.

The Tujia people also create their own architectural decorative art: "Shuaqi", handing columns, heads of Shuaqi and ends of hanging columns, 6-panel doors, and carved patterns windows. All of these have become striking characteristics of the stilted buildings of the $\mathrm{Tu}-$ jia people.

The carefully preserved stilted buildings in Pengjia Village have inherited the traditional features of the Tujia people's architectures. Based on a large number of our first-hand information through field research, ancient architecture surveying, and mapping in this village, in combination with our research in the Tujia areas over the 
past decade, the paper aims to record the real history and keep the local art and traditional technology.

Since the end of last century, rapid economic development in the past 20 years in China has resulted in the introduction of cheap undifferentiated concrete buildings in the Tujia area. Residents are faced with financial and natural resources challenges such as decreasing forests continuous rise of timber prices, and the rapidly dwindling number of skilled wood workers-conditions that force them to abandon traditional buildings. Additionally, the existing wooden structures need regular maintenance, such as having tiles replaced and being brushed with tung oil. Since large populations are migrant workers, many of the houses on stilts become empty nests. Without proper care, the stilted houses naturally collapse very easily. This constantly required care is what makes people give up on the stilted buildings. Local residents now tend to build simple concrete buildings with low costs rather than stilted buildings with complex wooden structures, thus the regional characteristics of the Tujia architecture are gradually disappearing.

In the past five years, highway extensions and railway construction have brought large number of tourists to the Tujia area [15,17]. Visitors revel in the beautiful natural scenery, while simultaneously marveling at these stilted building clusters integrated with the landscape. This has led the government to focusing on the return of traditional building methods in an attempt to attract more visitors in order to meet the tourism demands and promote economic development in the Tujia villages such as Pengjia.

For example, starting in 2008 in the EnshiTujia Autonomous Prefecture, Hubei Province, the government began to restore the stilted buildings gradually from three aspects to maintain the rural traditional regional characteristics.

The first priority is to protect the integrity of ancient villages, such as the Pengjia Village, as articulated in this paper. Our team for example has performed measured drawings, photographed every ancient building in the village, established original files for them, set up protection signs, and stationed protection mechanisms to protect the village. Demolition, reconstruction, and new building construction are strictly prohibited in the ancient village, and special funds will be allocated for the repairing and reinforcement of these irreplaceable cultural resources. To protect the ancient architecture, special attention has also been paid to the village environment and village culture, e.g., the restoration of riverine and mountain vegetation, and support of the traditional dances and customs of Pengjia Village as intangible cultural heritage. Such examples include the "Hands Waving Dance", "Drum Melody for Weeding", and "Xuanen Play". Tourists are invited to participate in the dances to experience the true traditional culture and meaning of the dances (Figure 14).

The second priority is to construct new buildings in the traditional way. The construction of new villages and expansion of existing villages in Tujia area require planning and construction following traditional ideas, which is completely out of the ordinary compared to commercial development modes. Planners need to extract and recombine traditional elements based on meticulous research on traditional Tujia villages (such as the windows, doors, roof, balcony, shrines and other elements as mentioned in the paper) and cooperate with the traditional woodworkers. For example, our research team has made numerous explorations and conducted various experiments in the design of the Pengjia Village Visitor Center, Qingyang Dam Ancient Village Renovation, Yumuzhai Ancient Village Planning (Figure 15). In addition, we highly encouraged the local residents to participate in together with the Tujia building construction professional team. Using these approaches, we hoped to encourage the residents to consciously build and maintain the traditional wood structure buildings. In the meantime, the local government pays subsidies on the increased cost causing by building the complexity of the stilted buildings.

The third priority is to restore and apply the traditional style onto discordant architecture. The local government describes it as "dressing up" the building, and this is mainly targeted at the large number of newly built rough concrete buildings at the end of last century. People have begun to add wooden roof structures at the top of the concrete structure, fitted them with wooden battens for the exterior wall, replaced the concrete balcony railings with suspension columns, Shuaqi, and head of Shuaqi used in the balcony of Tujia people, and replaced the aluminum alloy doors and windows with unique Tujia six-panel doors and bang doors. With this treatment, the exterior of the buildings that cannot be removed now has a traditional cover and is harmonious with the surrounding ancient villages (Figure 16).

We are applying our research through active involvement in the protection of settlements with Tujia characteristics and construction practices. The purpose of this ongoing initiative is to preserve the regional characteristics

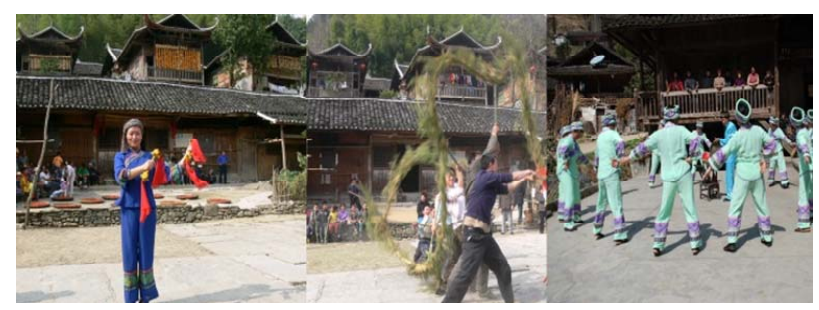

Figure 14. Protection of traditional buildings and folk customs picture by Kui Zhao, 2011. 


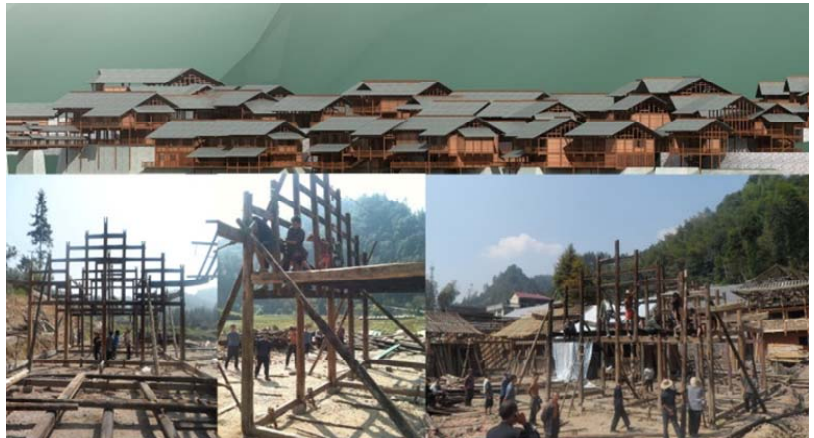

Figure 15. Directing Tujia people to build new stilted buildings using authentic traditional techniques picture by Kui Zhao, 2010.

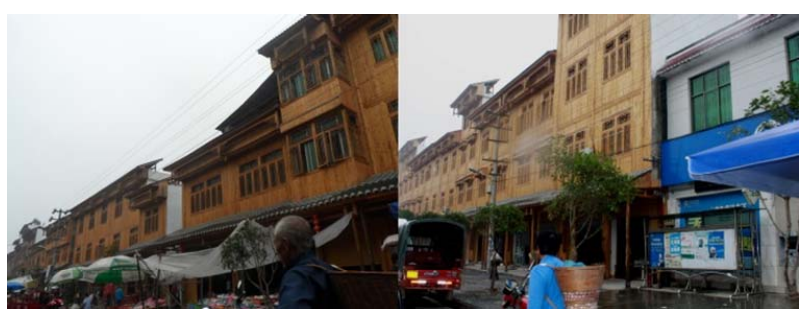

Figure 16. "Dress up" the discordant architecture picture by Kui Zhao, 2011.

of Tujia buildings and to help the international community understand the unique architectural forms of this ethnic group in inland China.

Ultimately, it is the inherent beauty of traditional Tujia architecture that demands that we share this research to protect and preserve the Tujia villages for future generations.

\section{Acknowledgements}

The research was sponsored by the National Natural Science Foundation of China (No. 50978111).

\section{REFERENCES}

[1] K. Zhao, "Sichuan Salt Trail-Architecture and Village in the Field of Vision of the Cultural Route," Southeast University Press, Nanjing, 2008.

[2] D. Luo and K. Zhao, "Southwest Residential," Tsinghua University Press, Beijing, 2009.

[3] K. Zhao and M. Wan, "Hubei Xuan'enPengjia Village,” Journal of Urban Planning, Vol. 3, No. 8, 2009, pp. 5052.

[4] M. F. Zhong, "Research on Traditional Stone Buildings in West Hunan Rural Areas,” Advanced Materials Research,
Vol. 450, No. 2, 2012, pp. 218-222.

[5] C. Zhou, "Spatial Features of the Traditional Vernacular Dwelling in Three Gorges Area," Journal of Anhui Agricultural Sciences, Vol. 25, No. 3, 2011, pp. 122-124.

[6] X. H. Liu and J. Jia, "Sustainable Development of Tujia People's 'Diaojiaolou' House in Southwest of Chongqing,” International Conference on Multimedia Technology (ICMT), Hangzhou, 26-28 July 2011, pp. 12611264.

[7] J. Zheng and J. Yu, "Preservation and Utilization of Traditional Inhabited Areas in the North of Guangxi-With Ping'an Village in Longsheng County, Guilin City as an Example,” Planner, Vol. 8, No. 1, 2006, pp. 56-58.

[8] Y. H. Lin, "New Rural Construction Tujia Stilted Development and Application,” Nanjing Arts Institute (Art and Design), Nanjing, 2010, pp. 6-12.

[9] Q. Lu, “Tujia Residential Characteristics and Formation,” Huazhong Architecture, Vol. 2, No. 3, 1996, pp.69-74.

[10] F. Peng, "Buildings on Stilts to Peng ZhaiTujia Traditional Houses about the Value and Protection," Journal of Development of Small Cities \& Towns, Vol. 1, No. 2, 2011, pp. 2-7.

[11] Y. Sun and T. Lin, "Building Technology and Art of Tujia Houses in the Southeast Chongqing,” Chongqing Jianzhu University, Chongqing, 2006, pp. 2-5.

[12] Y. Wang and Y. Zheng, "Western Hubei TujiaXuan'en Characteristics and Protection of Residential Houses on Stilts,” Huazhong Architecture, Vol. 7, No. 5, 2005, pp. 31-35.

[13] M. Y. Xiang, Y. K. Yuan and Y. Huang, “Tujia Architectural Style Remediation Practices: Case Study of Qianjiang Ancient Water Town,” Art and Design, Vol. 19, No. 7, 2009, pp. 79-83.

[14] Y. H. Xin and B. Luo, "On the Cultural-Permeation between Tu and Han Nationality from the Perspective of Wood-Carving in Furniture of Wulin Religion," Huazhong Normal University (Humanities and Social Sciences), Wuhan, 2004, pp. 10-22.

[15] Y. Q. Yao, "Aesthetical Study of Tujia Residential Architectures,” Shanxi Architecture, Vol. 1, No. 7, 2004, pp. 13-17.

[16] W. Zhao, "Three Gorges Residential Courtyards StudyAn Analysis Reservoir Republican Courtyard Space Morphology Evolution,” Chongqing Architecture University, Chongqing, 2000, pp. 100-108.

[17] Y. P. Zhou and Q. Y. Li, “Analysis of Cultural Integration in the Evolution of Western Hubei Tujia Houses," Chinese and Overseas Architecture, Vol. 3, No. 3, 2012, pp. 23-31. 